\title{
Resíduos orgânicos agropecuários e biodigestores: análise sobre a produção bibliográfica do período de 2000-2017
}

A destinação ambientalmente adequada de resíduos deve ser realizada em qualquer atividade antrópica, sendo assim, o setor agropecuário brasileiro tem esta pauta em destaque, principalmente, pela expansão e evolução que vem passando nas últimas décadas. Assim, o intuito deste trabalho foi evidenciar as pesquisas sobre a destinação de resíduos orgânicos agropecuários (RSOA) com ênfase na geração de energia por meio de biodigestores, respondendo as seguintes indagações: i) tipo de RSOA mais abordado; ii) escopo dos estudos; iii) a faixa de eficiência energética destes resíduos; iv) tipos de biodigestores utilizados. Este trabalho baseia-se em uma revisão sistemática de literatura sobre resíduos orgânicos e biodigestores, na qual os trabalhos foram obtidos em plataformas de busca renomadas, e os dados foram analisados por estatística descritiva. Os resultados obtidos demonstraram que o estudo de resíduos oriundos de produção animal predominou ( $83 \%)$, destacando-se os resíduos originários da suinocultura (34\%) e da bovinocultura (24\%). Notou-se a predominância dos estudos com o objetivo de avaliar a eficiência energética de RSOA (53\%), sendo a faixa de eficiência energética destes resíduos entre 0,00091 e 0,56 m3.kg-1. Nos estudos elencados, os biodigestores mais utilizados foram o tipo batelada de bancada (36\%) e o modelo canadense $(20 \%)$. O estudo com viés mais científico busca trabalhar com biodigestores de batelada de bancada devido à necessidade de repetições e uniformidade das unidades experimentais, ao passo que para atender a demanda de campo, nota-se o emprego de biodigestores modelo canadense. Portanto, a delimitação do objeto de estudo dos trabalhos analisados baseia-se nas condições técnico-científica, culturais, econômicas e sociais associadas à geração e destinação destes resíduos.

\section{Organic waste agricultural and biodigesters: analysis of bibliographic production from the period 2000-2017}

The environmentally appropriate disposal of waste must be performed by any anthropic activity, as such, the Brazilian agricultural sector has this score in particular due to the expansion and evolution that has been going on in recent decades. Thus, the purpose of this work was to highlight the research on the use of agricultura organic waste (AOW) with emphasis on the generation of energy through biodigesters, answering the following questions: i) type of AOW most addressed; ii) scope of studies; iii) the energy efficiency range of these wastes; iv) type of biodigester used. This work is based on a systematic review of the literature on biodigestion, in which the works were obtained in renowned search platforms, the data were analyzed by descriptive statistics. The results showed that the study of residues from animal production predominat (83\%), particularly important were the residues from pig farms (34\%) and cattle (24\%). The studies indicate the predominance of the studies with the objective of evaluating the energy efficiency of AOW (53\%), this being energy efficiency range between 0.00091 and $0.56 \mathrm{~m} 3 \mathrm{~kg}-1$. In the studied studies, the most used biodigestors were the batch type of bench (36\%) and the Canadian model (20\%). The study with a more scientific bias seeks to work on the benchmark batch biodigestors because of the need for repetitions and uniformity of the experimental units, while to meet the field demand, one notes the use of Canadian model biodigesters. Therefore, the delimitation of the object of study of the analyzed works is based on the technical-scientific, cultural, economic and social conditions associated to the generation and destination of this waste.

Keywords: Solid Waste; Renewable Energy; Recycling; Anaerobic Digestion.

Topic: Desenvolvimento, Sustentabilidade e Meio Ambiente

Reviewed anonymously in the process of blind peer.

José Bonifácio Martins Filho (id

Universidade Federal do Maranhão, Brasil http://lattes.cnpq.br/4819207696239648

http://orcid.org/0000-0002-9170-5350

boni.martins@outlook.com

Rafael Alves das Neves (id

Universidade Federal do Maranhão, Brasil

http://lattes.cnpq.br/3210042247879038

http://orcid.org/0000-0001-9036-2838

rafaelalves.99@hotmail.com

Jocelio dos Santos Araújo (iD

Universidade Federal do Maranhão, Brasil

http://lattes.cnpq.br/0728802364987190

http://orcid.org/0000-0002-2441-7340

jocelios@yahoo.com.br
Received: 10/06/2018

Approved: 24/07/2018

Gregori da Encarnação Ferrão

Universidade Federal do Maranhão, Brasi http://lattes.cnpq.br/4627304990166302

http://orcid.org/0000-0002-1740-6723

gregoriferrao@yahoo.com.br

Isabela Cristina Gomes Pires (iD)

Universidade de São Paulo, Brasi

http://lattes.cnpq.br/3393211586560026

http://orcid.org/0000-0002-9055-9435

icgpires@yahoo.com.br

\section{Referencing this:}

MARTINS FILHO, J. B.; NEVES, R. A.; ARAÚJO, J. S.; FERRÃO, G. E.; PIRES, I. C. G.. Resíduos orgânicos agropecuários e biodigestores: análise sobre a produção bibliográfica do período de 2000-2017. Revista Ibero Americana de Ciências Ambientais, v.9, n.5, p.281-293, 2018. DOI: http://doi.org/10.6008/CBPC2179-6858.2018.005.0025 


\section{INTRODUÇÃO}

O Brasil é reconhecido mundialmente como um dos maiores produtores de alimentos no mundo (FAO, 2015). A agricultura e pecuária brasileira foram evoluindo no decorrer das últimas décadas, o que viabilizou o aumento significativo da produtividade dos sistemas de produção vegetal e animal (CONTINI et al., 2010), todavia a alta escala de produção do país também acarreta, consequentemente, no aumento da geração de resíduos sólidos orgânicos agropecuários (RSOA), criando desafios aos produtores para o gerenciamento dos resíduos gerados em propriedades rurais.

O Plano Nacional de Resíduos Sólidos (PNRS) é um instrumento fundamental da Política Nacional de Resíduos Sólidos, que tem por finalidade apresentar diretrizes e estratégias para garantir a destinação ambientalmente adequada dos resíduos sólidos no país (BRASIL, 2010). No tocante à disposição final de resíduos oriundos de atividades agropecuárias, o PNRS (MMA, 2012) apresenta e defende ações estratégicas em busca de procedimentos sustentáveis para o tratamento e disposição dos RSOA, como a produção de energia por meio do reaproveitamento da biomassa através do processo de biodigestão anaeróbica de resíduos agrossilvilpastoris.

A biodigestão é uma alternativa sustentável, pois é um processo químico natural que ocorre de forma espontânea sem a presença de oxigênio, portanto, ela se dá em ambiente anaeróbico, para que as bactérias realizem a digestão da matéria orgânica (SOLANO et al., 2010). Esse processo se apresenta como uma tecnologia promissora para a destinação eficiente dos RSOA, pois o seu tratamento viabiliza a produção de subprodutos de valor econômico como o biogás e o biofertilizante (SILVA et al., 2013).

Os biodigestores são tecnologias antigas e utilizadas em muitos países. A China possui cerca de 7 milhões de biodigestores para conversão de dejetos e plantas em metano. Na Índia, a quantidade de biodigestores é de cerca de 750 mil, metade deles construídos após 1986 (BRAGA et al., 2013). Atualmente, o instrumento mais difundido referente ao uso de biodigestores para o tratamento de resíduos agropecuários tem sido o Plano Setorial de Mitigação e de Adaptação às Mudanças Climáticas para a Consolidação de uma Economia de Baixa Emissão de Carbono na Agricultura (Plano $A B C$ ) que menciona a biodigestão como uma alternativa para tratamento dos RSOA (MAPA, 2012).

Além do PNRS, o estímulo legal para o tratamento de resíduos sólidos é mencionado na Resolução CONAMA no 430 (2011) que versa sobre as condições de lançamento de poluentes em corpos hídricos, e na Política Nacional sobre Mudança do Clima (2009) que menciona o desenvolvimento de tecnologias para reduzir as emissões de Gases do Efeito Estufa (GEE's), porém, ambas não fazem alusão explícita do uso de biodigestores para tratamento de resíduos orgânicos ou para a mitigação dos GEE's.

As pesquisas brasileiras na área de biodigestão têm abrangido uma grande diversidade de biodigestores e RSOA para avaliar a sua eficiência na produção de biogás e biofertilizante. Portanto, a justificativa deste trabalho consiste em conhecer o status quo destas pesquisas científicas para compreender as tendências dos trabalhos, e assim possuir um diagnóstico da temática, colaborando para vislumbrar oportunidades de trabalhos a serem desenvolvidos. Nesse sentido, o objetivo deste trabalho é elencar os 
estudos científicos de biodigestão, evidenciando os RSOA utilizados, o enfoque principal das pesquisas, a faixa de eficiência energética destes resíduos bem como os tipos de biodigestores utilizados.

\section{MATERIAIS E MÉTODOS}

Este trabalho baseia-se em uma revisão sistemática de literatura (UNESP, 2015) sobre biodigestão, afim de investigar e elencar os principais resíduos orgânicos de diferentes atividades agropecuárias que são retratados em experimentos de biodegradação anaeróbica, o foco dos trabalhos, a eficiência energética, e quais os modelos de biodigestores utilizados para tal procedimento.

Realizou-se uma busca eletrônica em 5 plataformas de pesquisa científica, duas delas de acesso restrito (Scopus e Web of Science) e três de conteúdo público (Scielo, Buscador Coruja e SIBi-USP), em setembro de 2017, também foram utilizados livros que abordam a temática. As pesquisas nas plataformas limitaram-se aos trabalhos científicos em língua portuguesa, publicados em revista brasileira no período entre 2000 e 2017. As palavras-chave de busca utilizadas foram: 'agropecuária', 'biodigestão', 'biogás' e 'biofertilizante'. Apenas artigos científicos foram considerados, sendo desconsideradas teses, dissertações ou monografias. Reunidas as informações obtidas em planilha do software Excel, analisou-se os dados por estatística descritiva, a qual permitiu a interpretação das informações bem como a representação gráfica dos resultados.

\section{RESULTADOS E DISCUSSÃO}

Foram encontrados setenta e oito estudos, dos quais trinta e oito foram selecionados conforme critérios de seleção descrito em material e método para expressar uma visão ampla dos RSOA estudados no Brasil. Os resultados obtidos demonstraram que dentre os trabalhos avaliados predominou o estudo de resíduos oriundos de produção animal (84\%), enquanto que resíduos de origem vegetal são menos presentes (13\%) neste levantamento (Tabela 1 ).

Tabela 1: Artigos científicos sobre biodigestão entre 2000 e 2017.

\begin{tabular}{|c|c|c|c|c|}
\hline Autoria & Título & Resíduo & Biodigestor & Foco Principal \\
\hline \multicolumn{5}{|l|}{$2000-2005$} \\
\hline $\begin{array}{l}\text { Leite et al. } \\
\text { (2001) }\end{array}$ & $\begin{array}{l}\text { Bioestabilização anaeróbia de resíduos sólidos orgânicos } \\
\text { em reatores de batelada }\end{array}$ & $\begin{array}{l}\text { Vegetal (fruta, } \\
\text { verduras e } \\
\text { folhagens) }\end{array}$ & $\begin{array}{l}\text { Batelada } \\
\text { bancada }\end{array}$ & $\begin{array}{l}\text { Eficiência energética } \\
\text { e biofertilizante }\end{array}$ \\
\hline $\begin{array}{l}\text { Leite et al. } \\
\text { (2003) }\end{array}$ & $\begin{array}{l}\text { Tratamento de resíduos sólidos de centrais de } \\
\text { abastecimento e feiras livres em reator anaeróbio de } \\
\text { batelada. }\end{array}$ & Vegetal & Batelada & $\begin{array}{l}\text { Eficiência energética } \\
\text { e biofertlizante }\end{array}$ \\
\hline $\begin{array}{l}\text { Amaral et al. } \\
\text { (2004) }\end{array}$ & $\begin{array}{l}\text { Biodigestão anaeróbia de dejetos de bovinos leiteiros } \\
\text { submetidos a diferentes tempos de retenção hidráulica }\end{array}$ & Bovinos de leite & $\begin{array}{l}\text { Indiano e } \\
\text { chinês }\end{array}$ & Eficiência energética \\
\hline $\begin{array}{l}\text { Amorim et al. } \\
(2004)\end{array}$ & $\begin{array}{l}\text { Biodigestão anaeróbia de dejetos de caprinos obtidos nas } \\
\text { diferentes estações do ano }\end{array}$ & Caprino & Batelada & Eficiência energética \\
\hline $\begin{array}{l}\text { Mentz et al. } \\
(2004)\end{array}$ & $\begin{array}{l}\text { Viabilidade de ovos de Fasciola hepatica de bovinos em } \\
\text { sistema de biodigestão anaeróbia }\end{array}$ & Bovinos & $\begin{array}{l}\text { Tanque } \\
\text { cilíndrico }\end{array}$ & Biofertilizante \\
\hline $\begin{array}{l}\text { Souza et al. } \\
\text { (2005) }\end{array}$ & $\begin{array}{l}\text { Biodigestão anaeróbia de dejetos de suínos sob efeito de } \\
\text { três temperaturas e dois níveis de agitação do substrato - } \\
\text { considerações sobre a partida }\end{array}$ & Suínos & $\begin{array}{l}\text { Batelada } \\
\text { bancada }\end{array}$ & Eficiência energética \\
\hline \multicolumn{5}{|l|}{$2006-2010$} \\
\hline $\begin{array}{l}\text { Angonese et al. } \\
(2006)\end{array}$ & $\begin{array}{l}\text { Eficiência energética de sistema de produção de suínos } \\
\text { com tratamento dos resíduos em biodigestor }\end{array}$ & Suínos & $\begin{array}{l}\text { Tanques } \\
\text { cilíndricos }\end{array}$ & Eficiência energética \\
\hline $\begin{array}{l}\text { Angonese et al. } \\
\text { (2007) }\end{array}$ & $\begin{array}{l}\text { Potencial de redução de emissão de equivalente de } \\
\text { carbono de uma unidade suinícola com biodigestor }\end{array}$ & Suínos & $\begin{array}{l}\text { Tanques } \\
\text { cilíndricos }\end{array}$ & Eficiência energética \\
\hline
\end{tabular}




\begin{tabular}{|c|c|c|c|c|}
\hline $\begin{array}{l}\text { Esperancini et } \\
\text { al. (2007) }\end{array}$ & $\begin{array}{l}\text { Viabilidade técnica e econômica da substituição de fontes } \\
\text { convencionais de energia por biogás em assentamento } \\
\text { rural do estado de São Paulo }\end{array}$ & Suínos & Indiano & $\begin{array}{l}\text { Viabilidade } \\
\text { econômica }\end{array}$ \\
\hline $\begin{array}{l}\text { Orrico et al. } \\
(2007)\end{array}$ & $\begin{array}{l}\text { Caracterização e biodigestão anaeróbia dos dejetos de } \\
\text { caprinos }\end{array}$ & Caprinos & $\begin{array}{l}\text { Batelada } \\
\text { bancada }\end{array}$ & Biofertilizante \\
\hline $\begin{array}{l}\text { Ribeiro et al } \\
(2007)\end{array}$ & $\begin{array}{l}\text { Efeito da fonte proteica e do processamento físico do } \\
\text { concentrado sobre a terminação de bovinos jovens } \\
\text { confinados e o impacto ambiental dos dejetos }\end{array}$ & Bovinos & $\begin{array}{l}\text { Batelada } \\
\text { bancada }\end{array}$ & $\begin{array}{l}\text { Eficiência energética } \\
\text { e biofertlizante }\end{array}$ \\
\hline $\begin{array}{l}\text { Leite et al. } \\
\text { (2009) }\end{array}$ & $\begin{array}{l}\text { Tratamento anaeróbio de resíduos sólidos orgânicos com } \\
\text { alta e baixa concentração de sólidos }\end{array}$ & Resíduos vegetais & Batelada & Eficiência energética \\
\hline $\begin{array}{l}\text { Orrico Júnior et } \\
\text { al. (2009) }\end{array}$ & $\begin{array}{l}\text { Biodigestão anaeróbia de dejetos de suínos com e sem } \\
\text { separação da fração sólida em diferentes tempos de } \\
\text { retenção }\end{array}$ & Suínos & $\begin{array}{l}\text { Biodigestor } \\
\text { tubular }\end{array}$ & Eficiência energética \\
\hline Bueno (2010) & $\begin{array}{l}\text { Comparação entre biodigestores operados em escala piloto } \\
\text { para produção de biogás alimentado com estrume bovino. }\end{array}$ & Bovinos & $\begin{array}{l}\text { Batelada } \\
\text { bancada }\end{array}$ & Eficiência energética \\
\hline $\begin{array}{l}\text { Cervi et al. } \\
(2010)\end{array}$ & $\begin{array}{l}\text { Viabilidade econômica da utilização do biogás produzido } \\
\text { em granja suínícola para geração de energia elétrica. }\end{array}$ & Aves & Canadense & Eficiência energética \\
\hline $\begin{array}{l}\text { Duarte Neto et } \\
\text { al. } \\
(2010)\end{array}$ & $\begin{array}{l}\text { Implementação e avaliação de um biodigestor de produção } \\
\text { descontínua }\end{array}$ & Bovino & $\begin{array}{l}\text { Batelada de } \\
\text { campo }\end{array}$ & Eficiência energética \\
\hline $\begin{array}{l}\text { Orrico Júnior } \\
\text { (2010) }\end{array}$ & $\begin{array}{l}\text { Avaliação de parâmetros da biodigestão anaeróbia de } \\
\text { dejetos de suínos alimentados com dietas à base de milho } \\
\text { e sorgo. }\end{array}$ & Suínos & $\begin{array}{l}\text { Batelada } \\
\text { bancada }\end{array}$ & Biofertilizante \\
\hline $\begin{array}{l}\text { Orrico Júnior } \\
\text { et al. (2010) }\end{array}$ & $\begin{array}{l}\text { Influência da relação volumoso: concentrado e do tempo } \\
\text { de retenção hidráulica sob a biodigestão anaeróbia de } \\
\text { dejetos de bovinos. }\end{array}$ & Bovinos & $\begin{array}{l}\text { Batelada } \\
\text { bancada }\end{array}$ & Eficiência energética \\
\hline $\begin{array}{l}\text { Orrico Júnior et } \\
\text { al. (2010) }\end{array}$ & $\begin{array}{l}\text { Biodigestão anaeróbia dos resíduos da produção avícola: } \\
\text { cama de frangos e carcaças }\end{array}$ & Aves & $\begin{array}{l}\text { Batelada de } \\
\text { campo }\end{array}$ & Eficiência energética \\
\hline $\begin{array}{l}\text { Quadros et al. } \\
(2010)\end{array}$ & $\begin{array}{l}\text { Biodigestão anaeróbia de dejetos de caprinos e ovino sem } \\
\text { reator contínuo de pvc flexível. }\end{array}$ & Caprinos ovino & Canadense & Eficiência energética \\
\hline $\begin{array}{l}\text { Souza et al. } \\
(2010)\end{array}$ & $\begin{array}{l}\text { Biodegradação de resíduos lignocelulósicos gerados na } \\
\text { bananicultura e sua valorização para a produção de biogás. }\end{array}$ & Vegetal & $\begin{array}{l}\text { Batelada } \\
\text { bancada }\end{array}$ & Eficiência energética \\
\hline $\begin{array}{l}\text { Vivan et al. } \\
(2010)\end{array}$ & $\begin{array}{l}\text { Eficiência da interação biodigestor e lagoas de estabilização } \\
\text { na remoção de poluentes em dejetos de suínos }\end{array}$ & Suínos & Canadense & $\begin{array}{l}\text { Eficiência } \\
\text { energética }\end{array}$ \\
\hline $\begin{array}{l}\text { Xavier et al. } \\
(2010)\end{array}$ & $\begin{array}{l}\text { Parâmetros de dimensionamento para biodigestores } \\
\text { batelada operados com dejetos de vacas leiteiras com e } \\
\text { sem uso de inóculo. }\end{array}$ & Bovinos leiteiros & $\begin{array}{l}\text { Batelada de } \\
\text { campo }\end{array}$ & Aspetos construtivos \\
\hline \multicolumn{5}{|l|}{ 2011-2017 } \\
\hline $\begin{array}{l}\text { Martins, } \\
\text { Oliveira. (2011) }\end{array}$ & $\begin{array}{l}\text { Análise econômica da geração de energia elétrica a partir } \\
\text { do biogás na suinocultura }\end{array}$ & Suínos & Canadense & $\begin{array}{l}\text { Viabilidade } \\
\text { econômica }\end{array}$ \\
\hline $\begin{array}{l}\text { Oliveira et al. } \\
\text { (2011) }\end{array}$ & Biodigestão anaeróbia de efluente de abatedouro avícola & Aves & $\begin{array}{l}\text { Biodigestor } \\
\text { tubular }\end{array}$ & $\begin{array}{l}\text { Eficiência energética } \\
\text { e biofertilizante }\end{array}$ \\
\hline $\begin{array}{l}\text { Orrico et al. } \\
(2011)\end{array}$ & $\begin{array}{l}\text { Biodigestão anaeróbia dos dejetos de cabritos Saanen } \\
\text { alimentados com dietas com diferentes proporções } \\
\text { volumoso e concentrado }\end{array}$ & Caprinos & $\begin{array}{l}\text { Batelada } \\
\text { bancada }\end{array}$ & Biofertilizante \\
\hline $\begin{array}{l}\text { Farias et al. } \\
\text { (2012) }\end{array}$ & $\begin{array}{l}\text { Biodigestão anaeróbia de dejetos de poedeiras coletados } \\
\text { após diferentes períodos de acúmulo }\end{array}$ & Aves & $\begin{array}{l}\text { Batelada de } \\
\text { bancada }\end{array}$ & Eficiência energética \\
\hline $\begin{array}{l}\text { Orrico Júnior et } \\
\text { al. (2012) }\end{array}$ & $\begin{array}{l}\text { Biodigestão anaeróbia dos dejetos da bovinocultura de } \\
\text { corte: influência do período, do genótipo e da dieta. }\end{array}$ & Bovinos & $\begin{array}{l}\text { Batelada } \\
\text { bancada }\end{array}$ & Eficiência energética \\
\hline $\begin{array}{l}\text { Silva et al. } \\
(2012)\end{array}$ & $\begin{array}{l}\text { Avaliação físico-química de efluente gerado em biodigestor } \\
\text { anaeróbio para fins de avaliação de eficiência e aplicação } \\
\text { como fertilizante agrícola. }\end{array}$ & Suínos & Canadense & $\begin{array}{l}\text { Eficiência energética } \\
\text { e biofertilizante }\end{array}$ \\
\hline $\begin{array}{l}\text { Avaci et al. } \\
(2013)\end{array}$ & $\begin{array}{l}\text { Avaliação econômico-financeira da microgeração de } \\
\text { energia elétrica proveniente de biogás da suinocultura }\end{array}$ & Suínos & Canadense & $\begin{array}{l}\text { Viabilidade } \\
\text { econômica }\end{array}$ \\
\hline $\begin{array}{l}\text { Silva et al. } \\
(2013)\end{array}$ & $\begin{array}{l}\text { Biodigestão anaeróbia com substrato formado pela } \\
\text { combinação de esterco ovinocaprino, manipueira e } \\
\text { biofertilizante }\end{array}$ & $\begin{array}{l}\text { ovinocaprino } \\
+ \\
\text { manipueira }\end{array}$ & Indiano & $\begin{array}{l}\text { Eficiência energética } \\
\text { e biofertilizante }\end{array}$ \\
\hline $\begin{array}{l}\text { Rodrigues et al. } \\
(2014)\end{array}$ & $\begin{array}{l}\text { Adição de óleo e lipase sobre a biodigestão anaeróbia de } \\
\text { dejetos suínos }\end{array}$ & Suínos & $\begin{array}{l}\text { Batelada de } \\
\text { bancada }\end{array}$ & $\begin{array}{l}\text { Eficiência energética } \\
\text { e biofertilizante }\end{array}$ \\
\hline $\begin{array}{l}\text { Cancelier et al. } \\
(2015)\end{array}$ & $\begin{array}{l}\text { Avaliação da produção de biogás de dejetos de suínos } \\
\text { utilizando a metodologia de superfície de resposta }\end{array}$ & Suínos & $\begin{array}{l}\text { Batelada } \\
\text { bancada }\end{array}$ & Eficiência energética \\
\hline $\begin{array}{l}\text { Quadros et al. } \\
\text { (2015) }\end{array}$ & $\begin{array}{l}\text { Análise econômica do biodigestor para aproveitamento dos } \\
\text { dejetos da caprinocultura na agricultura familiar nordestina }\end{array}$ & Caprino & Canadense & $\begin{array}{l}\text { Viabilidade } \\
\text { econômica }\end{array}$ \\
\hline $\begin{array}{l}\text { Tessaro et al. } \\
(2015)\end{array}$ & $\begin{array}{l}\text { Potencial energético da cama de aviário produzida na } \\
\text { região sudoeste do Paraná e utilizada como substrato para } \\
\text { a produção de biogás }\end{array}$ & Aves & Indiano & $\begin{array}{l}\text { Eficiência energética } \\
\text { e biofertlizante }\end{array}$ \\
\hline $\begin{array}{l}\text { Orrico et al. } \\
(2016)\end{array}$ & $\begin{array}{l}\text { Codigestão anaeróbia dos dejetos de bovinos leiteiros e } \\
\text { óleo de descarte }\end{array}$ & Bovinos d & $\begin{array}{l}\text { Batelada } \\
\text { bancada }\end{array}$ & Eficiência energética \\
\hline
\end{tabular}




\begin{tabular}{|c|c|c|c|c|}
\hline $\begin{array}{l}\text { Victorino et al. } \\
\text { (2016) }\end{array}$ & $\begin{array}{l}\text { Biotecnologia e sustentabilidade: potencial de digestão } \\
\text { anaeróbia na redução de resíduos, na produção de energia } \\
\text { e de biofertizantes }\end{array}$ & $\begin{array}{l}\text { Resíduos vegetais } \\
\text { (Alimentos) }\end{array}$ & $\begin{array}{l}\text { Biodigestor } \\
\text { tubular }\end{array}$ & Eficiência energética \\
\hline $\begin{array}{l}\text { Damaceno } \\
\text { (2017) }\end{array}$ & $\begin{array}{l}\text { Aproveitamento agronômico e energético de dejeções } \\
\text { suinícolas: estudo de caso com análise econômico- } \\
\text { financeira }\end{array}$ & Suínos & Canadense & $\begin{array}{l}\text { Viabilidade } \\
\text { econômica }\end{array}$ \\
\hline
\end{tabular}

O maior número de publicações, no período analisado, ocorreu no ano de 2010 , com $26 \%$ de artigos. Os anos de 2001, 2003, 2005, 2006, 2014 e 2017 apresentaram a menor quantidade de artigos científicos publicados, $2 \%$ cada ano (Figura 1 ).

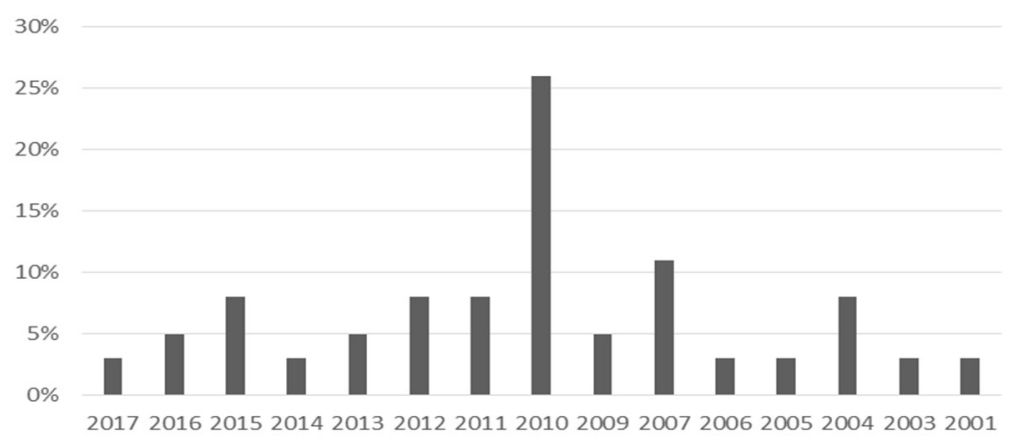

Figura 1: Ano das publicações.

Acredita-se que a maior quantidade de trabalhos publicados em 2010 seja um reflexo dos objetivos traçados em tratados internacionais para a preservação do meio ambiente, como exemplo o Protocolo de Quioto, que propõe a redução de GEE's. Nesse sentido, ao plano $A B C$ também se pode atribuir importância nesse cenário, haja visto que foi um plano desenvolvido em 2010 para redução de gases poluentes pela agropecuária brasileira (MAPA, 2012). Embora os estudos brasileiros nessa área estejam voltados em sua grande maioria para biodigestão de dejetos de animais, salienta-se que é possível produzir biogás e biofertilizante a partir de uma ampla gama de culturas energéticas como o girassol, o milho e trigo (ADERIBIGBE, 2015).

Entre os fatores que justificam a maior frequência do estudo da biodigestão de excremento animal, cita-se a facilidade no tratamento, uma vez que os dejetos de animais já passaram por um processo de digestão no intestino do animal, e ressalta-se ainda que tais dejetos quando descartados incorretamente podem contaminar água, solo e atmosfera (AVACl et al., 2013), prática que é proibida por lei, incorrendo em sanções cabíveis por crime ambiental (BRASIL, 1998).

Embora a destinação mais comum do estrume no mundo seja, simplesmente, a aplicação no solo (KUNZ et al., 2005), há outras maneiras de uso racional dos RSOA. Portanto, entende-se que os biodigestores se apresentam como uma alternativa para evitar o desacato à lei ambiental pela perspectiva da responsabilidade ambiental, uma vez que esta destinação final é a mais adequada ambientalmente para estes resíduos, pois evita impactos negativos ao ambiente e gera biogás e biofertilizante. Dentre os RSOA utilizados para biodigestão destacam-se os resíduos oriundos da suinocultura, $34 \%$, e da bovinocultura, $24 \%$ (Figura 2). 


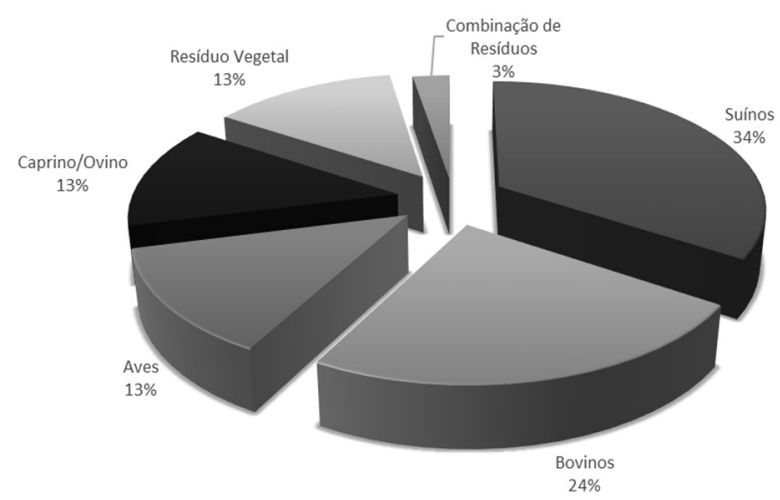

Figura 2:Tipos de resíduos sólidos orgânicos agropecuários em \%.

A ênfase das pesquisas esteve sobretudo na avaliação da eficiência energética da produção de biogás pela decomposição da matéria orgânica (53\%), 3\% dos estudos avaliaram aspectos construtivos dos biodigestores e $13 \%$ a questão econômica da implantação de biodigestores, fatores como custos de produção, prazo de retorno de investimento e, de maneira geral, a viabilidade econômica do uso do biodigestor no tratamento de resíduos (Tabela 1 ).

\section{Resíduos de origem animal - o caso da suinocultura}

O Brasil produz cerca de 3,2 mil toneladas de carne suína anualmente, portanto, se destaca como um dos maiores do mundo nesse segmento, a região Sul é a maior produtora e exportadora do país, produzindo 49\% de toda a carne suína do país e exportando 83\% desse total (SEBRAE, 2016). Os resíduos gerados pela suinocultura são os mais estudados com $34 \%$ de representação do total de artigos levantados. A valorização dos estudos para esse resíduo pode estar ligada a expressividade da produção de carne suína no país e pelo fato da cultura ser considerada atividade potencialmente causadora de poluição ambiental pelos órgãos ambientais (KLEIN et al., 2012; IAP, 2017), logo os empreendimentos nesse segmento devem adotar medidas para o tratamento e descarte dos resíduos gerados.

Os excrementos de suínos embora apresentem alto teor de nutrientes e elevado potencial de poluição de solo, água e atmosfera, podem ser uma alternativa energética promissora para a suinocultura (OLIVEIRA, 1993) desde que os dejetos sejam manejados corretamente. A eficiência energética destes resíduos pode variar de 0,011 a $0,56 \mathrm{~m}^{3} \cdot \mathrm{kg}^{-1}$ (Tabela 2 ).

Tabela 2: Potencial de geração de biogás a partir de dejetos de suínos.

\begin{tabular}{|l|l|}
\hline Fonte & Produção de Biogás $\left(\mathrm{m}^{3} \cdot \mathrm{kg}^{-1}\right)$ \\
\hline Sganzerla (1983) & 0,56 \\
\hline Oliver (2008) & $0,075-0,089$ \\
\hline Souza (2005) & 0,04124 \\
\hline Orrico Júnior (2010) & $0,011-0,026$ \\
\hline
\end{tabular}

A importância da suinocultura para a economia brasileira é explicita, entretanto, o passivo ambiental que atividade pode gerar a longo prazo é bastante impactante ao meio ambiente (OLIVEIRA, 2004), todavia a evolução do sistema de produção e a adoção de práticas gerenciais (gestão de insumos e resíduos) que ocorreram ao longo das últimas décadas foram significativas para o aumento da produtividade das granjas suinícolas e para sustentabilidade da produção (ABCS, 2016). 


\section{Resíduos de origem animal: o caso da bovinocultura}

O Brasil se destaca na produção de carne bovina, sendo um dos mais importantes produtores e exportadores no mundo (EMBRAPA, 2018c). O rebanho bovino brasileiro é o segundo maior do planeta, atrás apenas da Índia, e em 2015 alcançou a marca de 215,2 milhões de cabeças (IBGE, 2015). Além disso, o Brasil é também um dos maiores confinadores de bovinos, com mais de 2 milhões de animais confinados (ASSOCON, 2010).

Ao considerar que um bovino em sistema de produção confinado gera em média $15 \mathrm{~kg}$ de dejetos diariamente (OLIVER, 2008), é possível estimar a produção de dejetos em mais de 30 milhões de excrementos de animal por dia em âmbito nacional. A partir desta estimativa, nota-se que é fundamental definir a destinação final adequada destes resíduos para redução de impactos ambientais que a atividade pode causar. O potencial de produção de biogás por dejetos de bovinos pode variar entre 0,0233 e 0,27 $\mathrm{m}^{3} \cdot \mathrm{kg}^{-1}$ (Tabela 3). Para Spadotto et al. (2006), o fato do Brasil deter um grande rebanho de bovinos justifica os estudos relacionados a bovinocultura e o meio ambiente, haja visto que são animais que naturalmente emitem metano.

Tabela 3: Potencial de geração de biogás a partir dejetos de bovinos.

\begin{tabular}{|l|l|l|}
\hline Fonte & Aptidão & Produção de Biogás $\left(\mathrm{m}^{3} \cdot \mathrm{kg}^{-1}\right)$ \\
\hline Sganzerla (1983) & Corte & 0,27 \\
\hline Oliver (2008) & Corte & 0,040 \\
\hline Oliver (2008) & Leite & $0,040-0,049$ \\
\hline Amaral et al. (2004) & Leite & $0,0233-0,0279$ \\
\hline
\end{tabular}

\section{Resíduos de origem vegetal}

A decomposição de resíduos vegetais é dificultada pela presença de lignina, pois é um composto de difícil degradabilidade, sendo necessário previamente ao processo de biodigestão algum pré-tratamento para facilitar a degradação do material lignolelulósico (CREMONEZ et al., 2013). Existem diversos métodos para realizar o pré-tratamento de materiais lignocelulósicos anterior ao processo de biodigestão anaeróbica, esses métodos podem ser de caráter físico, físico-químico, químico e enzimático (COSTA et al., 2014), eles têm o objetivo de facilitar o processo de degradação devido aos empecilho estruturais presentes nas plantas, para que as bactérias no interior do biodigestor possam decompor a biomassa mais rápido, dessa maneira influenciando na eficiência do processo de produção de biogás (FERNANDES et al., 2009).

Por essa perspectiva entende-se que os resíduos da produção vegetal não se apresentam tão atraente para biodigestão quanto os de origem animal, em função da possibilidade de utilizar os restos culturais vegetais para fins menos complexos ou que demandam menos trabalho, além de não haver a preocupação como passivo ambiental.

Os resíduos vegetais quando descartados no solo não apresentam riscos de contaminação, ao contrário, restos culturais de plantas são comumente utilizados para proteger o solo contra erosão, através de técnicas como a adubação verde e cobertura morta ou mulching prática essencial para a manutenção da 
umidade do solo, e ambas fundamentais para o fornecimento de nutrientes para o solo (RAMALHO FILHO; BEEK, 1983).

A composição química dos substratos orgânicos utilizados para a fermentação anaeróbica influencia na produtividade do biogás, haja visto que os resíduos vegetais provenientes de diferentes culturas terão composição química variáveis, portanto, é previsível a diferença de produtividade do biogás gerado a partir da biodigestão de diferentes resíduos de vegetais (SOUZA, 2010) essa diferenciação no potencial de geração de biogás pode variar entre 0,00090 a $0,38 \mathrm{~m}^{3} \cdot \mathrm{kg}^{-1}$ (Tabela 4).

Tabela 4: Potencial de geração de biogás a partir de resíduos vegetais.

\begin{tabular}{|l|l|l|}
\hline Fonte & Substrato & Eficiência $\left(\mathrm{m}^{3} \cdot \mathrm{kg}^{-1}\right)$ \\
\hline Sganzerla (1983) & Palha de feijão & 0,38 \\
\hline Sganzerla (1983) & Palha de soja & 0,30 \\
\hline Souza et al. (2010) & Banana & 0,244 \\
\hline Leite et al. (2003) & Feira livre & 0,00090771 \\
\hline Embrapa (2018a) & Resíduos vegetais & 0,04 \\
\hline
\end{tabular}

A liderança de produção de biogás no mundo é atribuída a União Europeia, que apresenta uma produção de 10 mil toneladas equivalente de petróleo por ano, sendo a Alemanha o país deste continente que mais tem progredido na produção de biogás inclusive com o uso de matéria orgânica vegetal (RABONI, URBINI, 2014).

\section{Combinação de resíduos}

Apesar da literatura relatar maior eficiência energética a partir da combinação de resíduos de origem animal e vegetal neste estudo, 97\% deles realizaram a experimentação com apenas um determinado resíduo, o restante 3\% avaliaram a biodigestão a partir da mistura de resíduo animal e vegetal (Tabela 1). Estudos reforçam a hipótese de que combinar diferentes tipos de substratos para diversificar e equilibrar a proporção de nutrientes no interior do biodigestor viabiliza melhores condições para o crescimento de comunidades microbianas responsáveis pela degradação da matéria orgânica, portanto, não é recomendado usar um único tipo de substrato (SOLANO et al., 2016).

\section{Diversidade de biodigestores}

Nos estudos levantados os biodigestores mais utilizados foram o tipo Batelada bancada (36\%), seguidos por biodigestores modelo Canadenses (20\%). Foi possível observar a utilização de estruturas improvisadas (tanques cilíndricos) para operarem como biodigestores em alguns trabalhos (8\%) (Figura 3).

No que tange a diversidade dos biodigestores podem ser classificados pelo modelo, tipo e faixa de temperatura em que operam (mesofílica e termofílica). Existem diversos modelos de biodigestores desenvolvidos, os modelos mais difundidos são o Canadense, Chinês e Indiano (KUNZ et al., 2005). Atualmente, o modelo canadense (Figura 4) é mais utilizado em granjas de suínos, ele é caracterizado por ser horizontal, comprido e com seção transversal trapezoidal (EMBRAPA, 2018b) e também apresenta a vantagem de possuir menor custo de produção e operação (CALZA et al., 2015). 


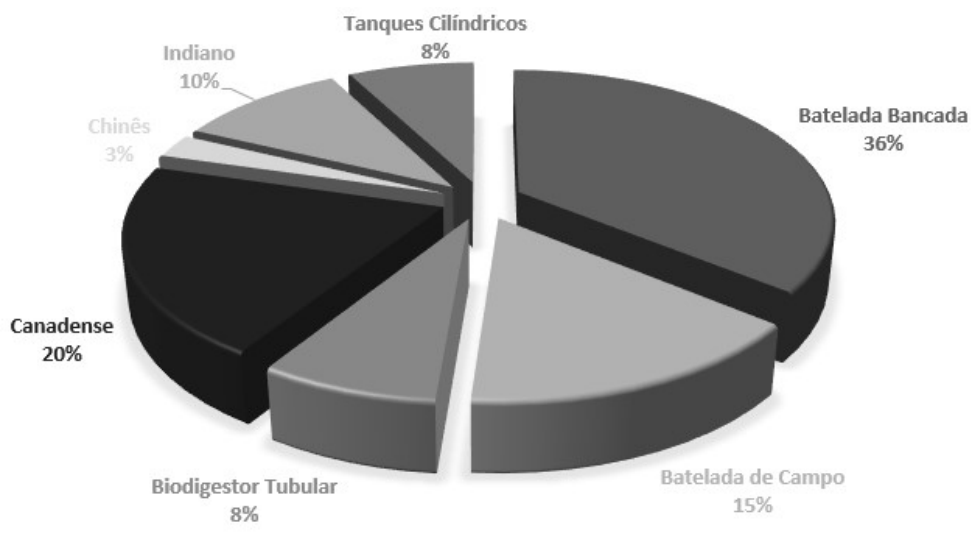

Figura 3: Tipos de biodigestores usados em experimentos de 2000 a 2017.

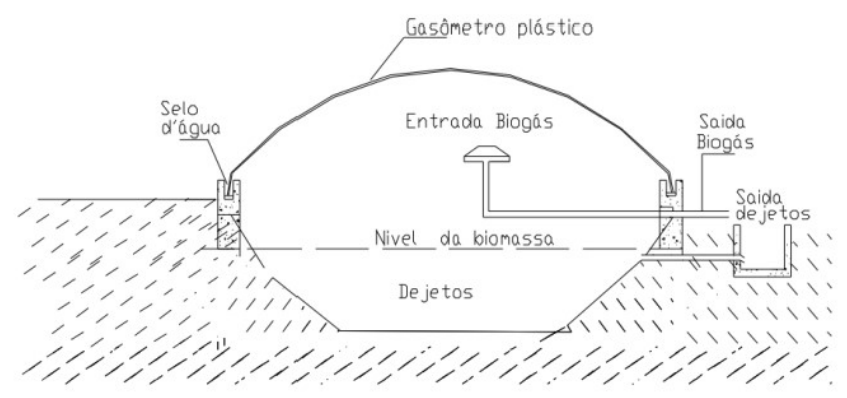

Figura 4: Biodigestor modelo Canadense (KUNZ et al., 2005).

Os biodigestores modelo Chinês são constituídos basicamente em alvenaria (Figura 5), possui um gasômetro em formato abobado impermeável com a função de armazenar biogás, e câmara de fermentação cilíndrica (DEGANUTTI et al., 2002). O modelo de biodigestor indiano é caracterizado por conter uma campânula como gasômetro (Figura 6), a qual desloca-se verticalmente para cima pela pressão do gás gerado (DEGANUTTI et al., 2002).

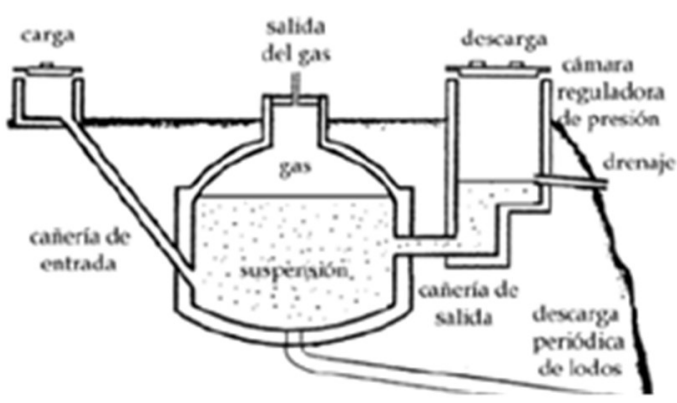

Figura 5: Biodigestor modelo Chinês (OLIVER, 2008).

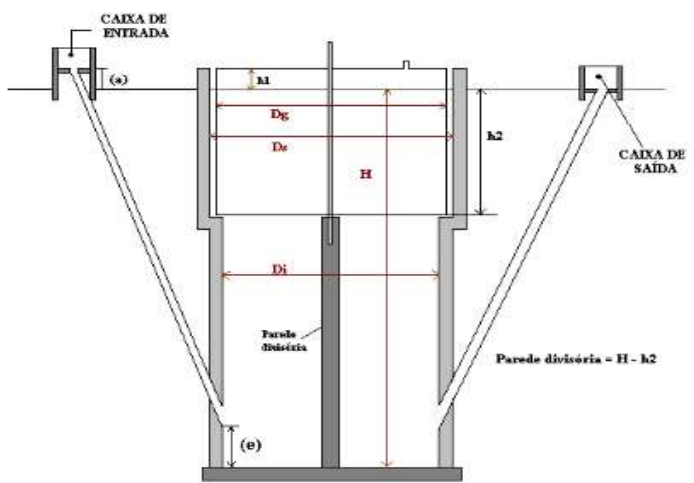

Figura 6: Biodigestor modelo canadense (DEGANUTTI et al., 2002). 
De acordo com a frequência que são abastecidos, podem ser chamados de contínuos quando são alimentados constantemente recebendo cargas diárias/periódicas, ou batelada (descontínuos) aqueles que são alimentados uma vez e a matéria a ser degrada fica condita durante o TRH (Tempo de Retenção hidráulica) requerido para a biodigestão (MACEDO, 2013). Operando de forma intermitente, o biodigestor modelo tubular também é conhecido como de batelada, e tem a vantagem de apresentar pouca exigência operacional (EMBRAPA, 2018b). Aqui apresentados separados, pois retrata a nomenclatura utilizada em cada artigo do levantamento.

Normalmente, os biodigestores descontínuos são os mais utilizados para a biodigestão de resíduos vegetais (VICTORINO et al., 2016; LEITE et al., 2003). A biomassa vegetal não possui a mesma praticidade dos dejetos de animais no que tange a coleta, abastecimento e descarregamento em biodigestores contínuos, logo os biodigestores de Batelada são mais indicados para essa matéria orgânica (SGANZERLA, 1983), sendo que o presente estudo reforça essa premissa, haja que visto que $100 \%$ dos trabalhos de biodigestão de resíduos vegetais fizeram uso de biodigestores de Batelada (Tabela 1).

Quanto faixa de temperatura em que funcionam, podem ser classificados como biodigestor mesofílico, com temperaturas entre 20 a 40 으 (ADERIBIGBE, 2015), e biodigestor termofílico operando sob o intervalo de temperatura de 50 a 65ㄷ (SOLARES et al., 2006). Os biodigestores mesofílicos, normalmente, são de custo inferior aos termofílicos pois podem operar em temperaturas de ambientes de clima tropical, como é o caso do Brasil (LANSING et al., 2008).

Para experimentos realizados em escala laboratorial, observou-se a utilização de biodigestores de pequeno porte, chamados de biodigestores de bancada em sua grande maioria avaliaram os aspectos relacionados a fatores químicos, físicos e biológicos da biodigestão, além de também viabilizar a repetibilidade e casualidade dos experimentos, tornando assim os resultados mais fidedignos pela perspectiva da estatística. Os biodigestores em escala industrial ou de maior porte, também chamados de biodigestores de campo objetivam relatar a eficiência energética e a viabilidade econômica da implantação dessa tecnologia para geração de energia e/ou biofertilizante.

De maneira geral, o fator que mais dificulta a implantação de biodigestores no Brasil é custo com a construção (CASTRO, CORTEZ, 1998), mas, há também inviabilidades técnicas características do país que são empecilhos para aproveitamento dos RSOA, entre elas destacam-se: transporte, equipamentos e a localização das unidades geradoras de RSOA, unindo-se a isso, o modelo e mercado elétrico nacional vigente dificultam iniciativas de empreendimentos energéticos (MMA, 2012).

\section{CONCLUSÕES}

As propostas de trabalhos que vislumbrem a combinação de resíduos de origem vegetal e animal são promissoras e possuem viabilidade técnica e econômica, porém foi a técnica menos aplicada nos trabalhos estudados. O estudo com viés mais científico busca trabalhar como biodigestores de batelada de bancada devido à necessidade de repetições e uniformidade das unidades experimentais, ao passo que para atender a demanda de campo, nota-se o emprego de biodigestores modelo canadense (grande porte e produção 
contínua). Portanto, observa-se que os aspectos técnico-científicos são importantes para a confecção e desenvolvimento de biodigestores, entretanto, os fatores culturais, econômicos e sociais relacionados à geração destes resíduos interferem na delimitação do objeto de estudo (tipo de resíduo e de biodigestor).

AGRADECIMENTOS: Os autores agradecem a Universidade Federal do Maranhão pela concessão de bolsa de iniciação cientifica (PIBIC) e tecnológica (PIBITI) aos graduandos

\section{REFERÊNCIAS}

ABCS. Associação Brasileira dos Criadores de Suínos. Mapeamento da suinocultura brasileira. Brasília, 2016.

ADERIBIGBE, A. B.. Design and construction of 250 liters plastic bio-digester and evaluation of biogas production using 4 co-substrates. IIOABJ, v.6, p.1-6, 2015.

AMARAL, C. M. C.; AMARAL, L. A.; LUCAS JÚNIOR, J.; NASCIMENTO, A. A.; FERREIRA, D. S.; MACHADO, M. R. F.. Biodigestão anaeróbia de dejetos de bovinos leiteiros submetidos a diferentes tempos de retenção hidráulica. Ciência Rural, Santa Maria, v.34, n.6, p.1897-1902, 2004.

AMORIM, A. C.; LUCAS JÚNIOR, J.; RESENDE, K. T.. Biodigestão anaeróbia de dejetos de caprinos obtidos nas diferentes estações do ano. Revista de Engenharia Agrícola, Jaboticabal, v.24, n.1, p.16-24, 2004.

ANGONESE, A. R.; CAMPOS, A. T.; ELTER, R. A. W.. Potencial de redução de emissão de equivalente de carbono de uma unidade suinícola com biodigestor. Revista de Engenharia Agrícola, Jaboticabal, v.27, n.3, p.648-657, 2007.

ANGONESE, A. R.; CAMPOS, A. T.; ZACARKIM, C. E.; MATSUO, M. S. CUNHA, F.. Eficiência energética de sistema de produção de suínos com tratamento dos resíduos em biodigestor. Revista Brasileira de Engenharia Agrícola e Ambiental, v.10, n.3, p.745-750, 2006

ASSOCON. Associação Nacional dos Confinadores. Análises da criação de gado de corte em confinamento. Brasília, 2010.

AVACI, A. B.; SOUZA, S. N. M.; CHAVES, L. I.; NOGUEIRA, C. E. C.; NIEDZIALKOSKI, R. K.; SECCO, D.. Avaliação econômicofinanceira da microgeração de energia elétrica proveniente de biogás da suinocultura. Revista Brasileira de Engenharia Agrícola e Ambiental, Campina Grande, v.17, n.4, p.456462, 2013.

BRAGA, B.; HESPANHOL, I.; CONEJO, J. G. L.; MIERZINA, J. C.; BARROS, M. T. L.; SPENCER, M.; PORTO, M.; Nucci, N.; JULIANO, N.; EIGER, S.. Introdução a Engenharia Ambiental O desafio do desenvolvimento sustentável. 2 ed. São Paulo: Person Prentice Hall, 2013.

BRASIL. Lei n. 12.305: Altera a Lei no 9.605, de 12 de fevereiro de 1998. Institui a Política Nacional de Resíduos Sólidos. Brasília: DOU, 2010.

BRASIL. Lei no 9.605: Dispõe sobre as sanções penais e administrativas derivadas de condutas e atividades lesivas ao meio ambiente, e dá outras providências. Brasília: DOU, 1998.

BUENO, R. F.. Comparação entre biodigestores operados em escala piloto para produção de biogás alimentado com estrume bovino. HOLOS Environment, v.10 n.1, p.111-125, 2010.
CALZA, L. F.; LIMA, C. B.; NOGUEIRA, C. E. C.; SIQUEIRA, J. A. C.; SANTOS, R. F.. Avaliação dos custos de implantação de biodigestores e da energia produzida pelo biogás. Revista de Engenharia Agrícola, Jaboticabal, v.35, n.6, p.990-997, 2015.

CANCELIER, A.; SOTO, U. P. D.; COSTELLI, M. C.; LOPES, T. J.; SILVA, A.. Avaliação da produção de biogás de dejetos de suínos utilizando a metodologia de superfície de resposta. Eng Sanit Ambient., v.20, n.2, p.209-219, 2015.

CASTRO, L. R.; CORTEZ, L. A. B.. Influência da temperatura no desempenho de biodigestores com esterco bovino. R. Bras. Eng. Agríc. Ambiental, Campina Grande, v.2, n.1, p.97-102, 1998.

CERVI, R. G.; ESPERANCINI, M. S. T.; BUENO, O. C..

Viabilidade econômica da utilização do biogás produzido em granja suínícola para geração de energia elétrica. Revista de Engenharia Agrícola, Jaboticabal, v.30, n.5, p.831-844, 2010.

CONAMA. Conselho Nacional do Meio Ambiente. Resolução no 430: Dispõe sobre as condições e padrões de lançamento de efluentes, complementa e altera a Resolução $n$ 으57, de 17 de março de 2005, do Conselho Nacional do Meio Ambiente-CONAMA. Brasília: DOU, 2011.

CONTINI, E.; GASQUES, J. G.; ALVES, E. R. A.; BASTOS, E. T. Dinamismo da agricultura brasileira. Revista de Política Agrícola, Brasília, v.19, p.42-64, 2010.

COSTA, A. G.; PINHEIRO, F. G. C.; PINHEIRO, G. C.; SANTOS, A. B.; SANTAELLA, S. T.; LEITÃO, R. C.. Geração de metano a partir de resíduos lignocelulósicos oriundos da produção do biocombustível: revisão. Revista DAE, São Paulo, n.194, p.36-51, 2014. DOI: http://dx.doi.org/10.4322/dae.2014.003

CREMONEZ, P. A.; FEIDEN, A.; ZENATTI, D. C., M. P. CAMARGO, W. C. N.; ROSSI, E.; ANTONELLI, J.. Biodigestão anaeróbia no tratamento de resíduos lignocelulósicos. Revista Brasileira de Energias Renováveis, v.2, p.21-35, 2013.

DAMACENO, F. M.; HALMEMAN, M. C. R. 2, GONÇALVES, M. S.; MEDEIROS, F. V. S.. Aproveitamento agronômico e energético de dejeções suinícolas: estudo de caso com análise econômico-financeira. Revista Agro@mbiente, v.11, n.2, p.174-180, 2017.

DEGANUTTI, R.; PALHACI, M. C. J. P; ROSSI, M.; TAVARES, R.; SANTOS, C.. Biodigestores rurais: modelo indiano, chinês e batelada. In: IV ENCONTRO DE ENERGIA NO MEIO RURAL. Anais. Campinas: UNICAMP, 2002.

DUARTE NETO, E. D.; ALVARENGA, L. H.; COSTA, L. M.; NASCIMENTO, P. H.; SILVEIRA, R. Z.; LEITE, L. H. M.. Implementação e avaliação de um biodigestor de produção descontínua. Revista e-xacta, Belo Horizonte, v.3, n.2, p.3646, 2010. 
EMBRAPA. Empresa Brasileira de Pesquisa Agropecuária. Agroenergia. Brasília: EMBRAPA, 2018a.

EMBRAPA. Empresa Brasileira de Pesquisa Agropecuária. Biogás. Brasília: EMBRAPA, 2018b.

EMBRAPA. Empresa Brasileira de Pesquisa Agropecuária. Qualidade da carne bovina. Brasília: EMBRAPA, 2018c.

ESPERANCINI, M. S. T.; COLEN, F.; BUENO, O. C.; PIMENTEL, A. E. B.; SIM, E. J.. Viabilidade técnica e econômica da substituição de fontes convencionais de energia por biogás em assentamento rural do Estado de São Paulo. Eng. Agríc., v.27, n.1, p.110-118, 2007.

FARIAS, R. M.; ORRICO JUNIOR, M. A. P.; ORRICO, A. C. A.; GARCIA, R. G.; CENTURION, S. R.; FERNANDES, A. R. M.. Biodigestão anaeróbia de dejetos de poedeiras coletados após diferentes períodos de acúmulo. Ciência Rural, Santa Maria, v.42, n.6, p.1089-1094, 2012.

FERNANDES, T. V.; KLAASSE BOS, G. J.; ZEEMAN, G.; SANDERS, J. P. M.; VAN LIER, J. B.. Effects of thermochemical pre-treatment on anaerobic biodegradability and hydrolysis of lignocellulosic biomass. Bioresour. Technol., v.100, p.2575-2579, 2009

IAP. Instituto Ambiental do Paraná. Cartilha para licenciamento ambiental. Curitiba: IAP, 2017.

IBGE. Instituto Brasileiro de Geografia e Estatística. Produção da Pecuária Municipal. Brasília: IBGE, 2015.

KLEIN, C.; AGNE, S. A. A.. Fósforo: de nutriente à poluente. Revista eletrônica em gestão, educação e tecnologia ambiental, Santa Maria, v.8, n.8, p.1713-1721, 2012.

KUNZ, A.; OLIVEIRA, P. A.; HIGARASHI, M. M.. Biodigestor para o tratamento de dejetos de suínos: influência da temperatura ambiente. Comunicado Técnico, Embrapa/CNPSA, v.416, p.1-5, 2005.

LANSING, S.; VÍQUEZB, J.; MARTÍNEZC, H.; BOTEROD, R.; MARTIN, J..Quantifying electricity generation and waste transformations in a low-cost, plug-flow anaerobic digestion system. Ecological engineering, v.34, p.332-348, 2008.

LEITE, V. D.; LOPES, W. S.; PRASAD, S.. Bioestabilização anaeróbia de resíduos sólidos orgânicos em reatores de batelada. Revista Brasileira de Engenharia Agrícola e Ambiental, Campina Grande, v.5, n.1, p.119-123, 2001.

LEITE, V. D.; LOPES, W. S.; SOUSA, J. T.; PRASAD, S.; SILVA, S. A.. Tratamento anaeróbio de resíduos sólidos orgânicos com alta e baixa concentração de sólidos. Revista Brasileira de Engenharia Agrícola e Ambiental, Campina Grande, v.13, n.2, p.190-196, 2009.

LEITE, V. D.; SOUSA, J. T.; PRASAD, S.; LOPES, W. S.; ATHAYDE JÚNIOR, G. B.; DANTAS, A. M. M.. Tratamento de resíduos sólidos de centrais de abastecimento e feiras livres em reator anaeróbio de batelada. Revista Brasileira de Engenharia Agrícola e Ambiental, Campina Grande, v.7, n.2, p.318-322, 2003.

MACEDO, F. J.. Dimensionamento de biodigestores para tratamento de dejetos da produção suína. Trabalho de Conclusão de Curso (Graduação em Engenharia Sanitária e Ambiental) - Universidade Federal de Santa Catarina, Florianópolis, 2013.

MAPA. Ministério da Agricultura, Pecuária e Abastecimento. Plano Setorial de Mitigação e de Adaptação às Mudanças
Climáticas para a Consolidação de uma Economia de Baixa Emissão de Carbono na Agricultura. Brasília: MAPA, 2012.

MARTINS, F.M.; OLIVEIRA, P. A. V.. Análise econômica da geração de energia elétrica a partir do biogás na suinocultura. Revista de Engenharia Agrícola, Jaboticabal, v.31, n.3, p.477-486, 2011.

MENTZ, M.B.; WIEST, J.M.; GONÇALVES, P.C.. Viabilidade de ovos de Fasciola hepatica de bovinos em sistema de biodigestão anaeróbia. Arq. Bras. Med. Vet. Zootec., v.56, n.4, p.550-553, 2004.

MMA. Ministério do Meio Ambiente. PNRS - Plano Nacional de Resíduos Sólidos. Brasília: MMA, 2012.

OLIVEIRA, A. B. M.; ORRICO, A. C. A.; ORRICO JÚNIOR, M. A. P.; SUNADA, N. S.; CENTURION, S. R.. Biodigestão anaeróbia de efluente de abatedouro avícola. Rev. Ceres, Viçosa, v.58, n.6, p.690-700, 2011.

OLIVEIRA, P. A. V.. Manual de manejo e utilização dos dejetos de suínos. Concórdia: Embrapa Centro Nacional Suínos e Aves, 1993.

OLIVEIRA, P. A. V.. Tecnologias para o manejo de resíduos na produção de suínos: manual de boas práticas. Concórdia: Embrapa Suínos e Aves, 2004.

OLIVER, A. P. M.. Manual de treinamento em biodigestão. Brasília: Instituto Winrock, 2008.

ORRICO JÚNIOR, M. A. P.; ORRICO, A. C. A. LUCAS JÚNIOR, J.. Biodigestão anaeróbia dos resíduos da produção avícola: cama de frangos e carcaças. Revista de Engenharia Agrícola, Jaboticabal, v.30, n.3, p.546-554, 2010.

ORRICO JÚNIOR, M. A. P.; ORRICO, A. C. A. LUCAS JÚNIOR, J.. Biodigestão anaeróbia de dejetos de suínos com e sem separação da fração sólida em diferentes tempos de retenção. Revista de Engenharia Agrícola, Jaboticabal, v.29, n.3, p.474-482, 2009.

ORRICO JÚNIOR, M. A. P.; ORRICO, A. C. A.; LUCAS JÚNIOR, J.. Avaliação de parâmetros da biodigestão anaeróbia de dejetos de suínos alimentados com dietas à base de milho e sorgo. Revista de Engenharia Agrícola, Jaboticabal, v.30, n.4, p.600-607, 2010

ORRICO JÚNIOR, M. A. P.; ORRICO, A. C. A.; LUCAS JÚNIOR, J.. Influência da relação volumoso: concentrado e do tempo de retenção hidráulica sob a biodigestão anaeróbia de dejetos de bovinos. Revista de Engenharia Agrícola, Jaboticabal, v.30, n.3, p.386-394, 2010.

ORRICO JÚNIOR, M. A. P.; ORRICO, A. C. A.; LUCAS JUNIOR, J.; SAMPAIO, A. A. M.; FERNANDES, A. R. M.; OLIVEIRA, E. A.. Biodigestão anaeróbia dos dejetos da bovinocultura de corte: influência do período, do genótipo e da dieta. R. Bras. Zootec., Viçosa, v.41, n.6, p.1533-1538, 2012.

ORRICO, A. C. A.; LOPES, W. R. T.; MANARELLI, D. M.; ORRICO JUNIOR, M. A. P.; SUNADA, N. S.. Codigestão anaeróbia dos dejetos de bovinos leiteiros e óleo de descarte. Revista de Engenharia Agrícola, Jaboticabal, v.36, n.3, p.537-545, 2016.

ORRICO, A. C. A.; LUCAS JÚNIOR, J.; ORRICO JÚNIOR, M. A. P.. Caracterização e biodigestão anaeróbia dos dejetos de caprinos. Revista de Engenharia Agrícola, Jaboticabal, v.27, n.3, p.639-647, 2007.

ORRICO, A. C. A.; ORRICO JUNIOR, PREVIDELLI, M. A.; LUCAS JUNIOR, J.. Biodigestão anaeróbia dos dejetos de cabritos Saanen alimentados com dietas com diferentes proporções 
volumoso e concentrado. R. Bras. Zootec.,Viçosa, v.40, n.2, p.448-453, 2011.

QUADROS, D. G.; OLIVER, A. P. M.; REGIS U.; VALLADARES, R.. Análise econômica do biodigestor para aproveitamento dos dejetos da caprinocultura na agricultura familiar nordestina. Energ. Agric., Botucatu, v. 30, n.1, p.01-10, 2015.

QUADROS, D. G.; OLIVER, A. P. M.; REGIS, U.; VALLADARES, R.; SOUZA, P. H. F.; FERREIRA, E. J.. Biodigestão anaeróbia de dejetos de caprinos e ovinos em reator contínuo de pvc flexível. Brasileira de Engenharia Agrícola e Ambiental, v.14, n.3, p.326-332, 2010.

RABONI, M.; URBINI, G.. Production and use of biogas in Europe: a survey of current status and perspectives. Rev. Ambient. Água, Taubaté, v.9 n.2, p.191-202, 2014.

RAMALHO FILHO, A.; BEEK, K. J.. Sistema de avaliação da aptidão agrícola das terras. 3 ed. Rio de Janeiro: EMBRAPACNPS, 1995.

RIBEIRO, G. M.; SAMPAIO, A. A. M.; FERNANDES, A. R. M.; HENRIQUE, W.; SUGOHARA, A.; AMORIM, A. C.. Efeito da fonte protéica e do processamento físico do concentrado sobre a terminação de bovinos jovens confinados e o impacto ambiental dos dejetos. R. Bras. Zootec., Viçosa, v.36, n.6, p.2082-2091, 2007.

RODRIGUES, J. P.; ORRICO, A. C. A.; ORRICO JUNIOR, M. A. P.; SENO, L. O.; ARAÚJO, L. C.; SUNADA, N. S.. Adição de óleo e lipase sobre a biodigestão anaeróbia de dejetos suínos. Ciência Rural, Santa Maria, v.44, n.3, p.544-547, 2014.

SEBRAE. Serviço Brasileiro de Apoio à Micro e Pequenas Empresas. Minha Empresa Sustentável: Suinocultura. Cuiabá: Centro Sebrae de Sustentabilidade, 2016.

SGANZERLA, E.. Biodigestor uma solução. Porto Alegre: Agropecuária Ltda, 1983.

SILVA, C. O.; CEZAR, V. R. S.; SANTOS, M. B.; SANTOS, A. S. Biodigestão anaeróbia com substrato formado pela combinação de esterco ovinocaprino, manipueira e biofertilizante. Revista Ibero-Americana de Ciências Ambientais, Aracaju, v.4, n.1, p.88-103, 2013.

SILVA, W. T. L.; NOVAES, A. P.; KUROKI, V.; MARTELLI, L. F. A.; MAGNONI JÚNIOR, L.. Avaliação físico-química de efluente gerado em biodigestor anaeróbio para fins de avaliação de eficiência e aplicação como fertilizante agrícola. Quim. Nova, v.35, n.1, p.35-40, 2012.

SOLANO, O. R.; VARGAS, F. M.; WATSON, G. R.. Biodigestores: factores químicos, físicos y biológicos relacionados com suproductividad. Tecnología en Marcha, v.23, n.1, p.39-46, 2010.

SOLARES,T. E.; BOMBARDIERE, J.; CHATFIELD, M.; DOMASCHKO, M.; EASTER, M.; STAFFORD, D. A.; ANGELES, S. C.; HERNANDEZ, N. C.. Macroscopic mass and energy balance of a pilot plant anaerobic bioreactor operated under thermophilic conditions. Biochemistry and Biotechnology, n.6, v.129, p.959-968, 2006.

SOUZA, C. F.; LUCAS JÚNIOR, J.; FERREIRA, W. P. M.. Biodigestão anaeróbia de dejetos de suínos sob efeito de três temperaturas e dois níveis de agitação do substrato considerações sobre a partida. Revista de Engenharia Agrícola, Jaboticabal, v.25, n.2, p.530-539, 2005.

SOUZA, O.; FEDERIZZI, M.; COELHO B.; WAGNER, T. M.; WISBECK E.. Biodegradação de resíduos lignocelulósicos gerados na bananicultura e sua valorização para a produção de biogás. Revista Brasileira de Engenharia Agrícola e Ambiental, v.14, n.4, p.438-443, 2010.

SPADOTTO, C.; W, RIBEIRO.. Gestão de resíduos na agricultura e agroindústria. 1 ed. Botucatu: FEPAF, 2006.

TESSARO, A. B.; TESSARO, A. A.; CANTÃO, M. P.; MENDES, M. A.. Potencial energético da cama de aviário produzida na região sudoeste do paraná e utilizada como substrato para a produção de biogás. Rev. Agro. Amb., v.8, n.2, p. 357-377, 2015.

UNESP. Universidade Estadual Paulista 'Júlio de Mesquita Filho'. Tipos de revisão de literatura. Botucatu: Biblioteca Prof. Paulo de Carvalho Mattos, 2015.

VICTORINO, A.; VIANNA, J. N. S.; ZANETI, I. C. B. B.; VILARINHO, M. T. L.. biotecnologia e sustentabilidade: potencial de digestão anaeróbia na redução de resíduos, na produção de energia e de biofertizantes. Fronteiras: Journal of Social, Technological and Environmental Science, v.5, n.1, p.68-87, 2016

VIVAN, M.; KUNZ, A.; STOLBERG, J.; PERDOMO, C.; TECHIO, V. H.. Eficiência da interação biodigestor e lagoas de estabilização na remoção de poluentes em dejetos de suínos. Revista Brasileira de Engenharia Agrícola e Ambiental, Campina Grande, v.14, n.3, p.320-325, 2010.

XAVIER, C. A. N.; LUCAS JÚNIOR, J.. Parâmetros de dimensionamento para biodigestores batelada operados com dejetos de vacas leiteiras com e sem uso de inóculo. Revista de Engenharia Agrícola, Jaboticabal, v.30, n.2, p.212-223, 2010 .

A CBPC - Companhia Brasileira de Produção Científica (CNPJ: 11.221.422/0001-03) detém os direitos materiais desta publicação. Os direitos referem-se à publicação do trabalho em qualquer parte do mundo, incluindo os direitos às renovações, expansões e disseminações da contribuição, bem como outros direitos subsidiários. Todos os trabalhos publicados eletronicamente poderão posteriormente ser publicados em coletâneas impressas sob coordenação da Sustenere Publishing, da Companhia Brasileira de Produção Científica e seus parceiros autorizados. Os (as) autores (as) preservam os direitos autorais, mas não têm permissão para a publicação da contribuição em outro meio, impresso ou digital, em português ou em tradução. 